\title{
Maintaining Academic Connection for Collective Creativity: a Grounded Theory of University Teacher's Professional Behavior in Social Media
}

\author{
Judita KASPERIUNIENE \\ Vytautas Magnus University, Kaunas, Lithuania \\ judita.kasperiunieneevdu.lt
}

\begin{abstract}
Collective creativity develops in situations where creative self-regulated adults collaborate to create product or service. In this research we supported the ideas that collective creativity could happen at the level of the group, and at the level of the self-regulated adult. The results of collective creativity are often unpredictable. Social media sites are contemporary medium for collective creativity development. Communicating, discussing, sharing and participating, self-regulated adults construct their professional identities. Although it has been researched for several years, identity construction in social media sites remains one of the main areas of scholarly investigation. Our research question was - how (if all this is happening) university teachers developed collective creativity in social media. University teachers from 5 Lithuanian universities in 2 main cities participated in the research. Research participants were engaged in 5 scientific fields: sciences, social sciences, humanities, biomedicine and technologies. We have purposefully selected such university teachers who have been involved in social media activities. Teachers used Facebook, LinkedIn and Youtube for sharing, communicating and collaborating with their students, colleagues and other self-regulated adults. For the qualitative data collection interviews were conducted. We constructed grounded theory to explore university teacher professional development in social media. Three categories: exploratory behavior, online presence, curiosity and challenge showed the process of university teacher collective creativity. Text hunting, checking text validity, sharing and networking were preconditions that lead to maintaining academic connection for collective creativity. Maintaining academic connection helped to pursue professional goals and construct professional identity. These findings contributed to understanding how the university teacher's collective creativity developed in social media.
\end{abstract}

Keywords: academic connection, collective creativity, grounded theory, social media, university teacher's professional development

\section{Introduction}

Academic connection could be maintained in formal and informal ways. In informal social media environments such as Facebook, LinkedIn or other networks persons create and develop informal connection while communicating, sharing, publishing and advertising to individuals and groups. In social media environment, university teachers informally make bonds with their students and other academic colleagues. Creativity results from interaction between three systems: a set of social institutions, cultural 
domains and persons (Csikszentmihalyi, 2014). Creativity development could be analyzed as process, where participants develop new social, business or art models that later could be transposed and implemented in the new social contexts and network structures (Von Held, 2012). In scholarly literature different terms describing the process, when a few persons or a group are involved into creative activities, could be found: distributed creativity (Miettinen, 2006), collaborative creativity (Miell and Littleton, 2004), group (Paulus and Nijstad, 2003) and team creativity (Perry-Smith and Shalley. 2014). In this paper we supported Fischer and Vassen (2011) definition of collective creativity, stating that all creativity is collective, all the persons' creative selfexpression depends on the contribution of others and the creation of meaning can only proceed in dialogic interaction. Collective creativity could happen at many levels: at the level of the culture, at the level of the subculture, at the level of the group, and at the level of the self-regulated adult (Giuffre, 2016).

The concept of collective creativity flourished with new colors in networked society. The collective creativity is directly linked with flow when social media users experience emotional and cognitive challenges they want to repeat. To describe such social media engagement, Pelet et al. (2017) used flow concept, borrowed from Csikszentmihalyi (2014) and operationalized flow with five dimensions: concentration, enjoyment, control, challenge, and curiosity. In mediated environments, flow causes exploratory behavior. While in a flow, person wants to repeat the experience. Exploratory behavior leads to engagement and immersion that increase social media surfing time. Studies showed that networked flow could be achieved then research participants experienced high level of social presence (Gao and Bai, 2014). The investigation of the relationship among social network structure, flow and university student creative performance showed the positive relationship between all the components (Gaggioli et al., 2015). Pelet et al. (2017) empirically proved, that the social media visitor's immersion and online presence correlated with person's virtual concentration, overall enjoyment, curiosity and feelings of being challenged and in control.

University teacher professional development is a process which covers and is not limited to development new professional experiences; growing attitudes and skills; learning new pedagogical approaches and new educational techniques (Crawford, 2015). Modern university teachers use technologies in classes and, being engaged and immersed into social media, experience networked flow. While spending their out-ofclass time online, university teachers follow professional and technological advancements, learn new things and later in class share these science, technology and profession news with students. Professional development could be researched as ongoing self-regulated learning experience. In this learning, a university teacher is not left alone. In social media, professional, research, opinion and subject study groups could be found. Self-regulated persons follow and actively participate in these groups. Exploring the social media groups and joining group activities, they share professional experiences and learn from each other.

Communicating, discussing, sharing and participating, university teachers construct their professional identities. Although it has been researched for several years, identity construction in social media remains one of the main areas of scholarly investigation (Papacharissi, 2010). The aim of this paper was to present the grounded theory that explains university teacher behavior in social media environments. The research question was - how (if all this is happening) university teachers developed collective creativity in social media. 
The structure of the paper is following: in Section 2 empirical research methodology, participants, data collection, analysis and research ethics were presented. In Section 3 empirical findings were described and illustrated. Additionally, the process showing how university teachers maintained academic connection in social media was mapped. In Section 4 empirical results were compared with other scholars' empirical findings. Section 5 summarized the grounded theory of university teacher professional behavior in social media.

\section{Methods}

In our empirical study we developed constructivist grounded theory following Charmaz (2014) approach. The main constructivist theories could result in four different types - cognitive constructivism, radical constructivism, situated constructivism and coconstructivism (Mattar, 2018). For the research of collective creativity in social media processes we chose co-constructivism - quite new concept, which still has no precise and widely accepted definition in educational or psychological literature. We used definition of Reusser and Pauli (2015), stating that co-constructivism could be explained as the implication of social interaction, collaborative activity and seeking some sort of convergence, inter subjectivity, or shared understanding. Constructivist grounded theory was used for data collection and analysis.

Research participants and data collection. Research participants were twenty university professors and teachers from five Lithuanian universities operating in two main cities. Teacher backgrounds, as well as research and teaching fields were sciences, social sciences, humanities, biomedicine and technologies. We conducted purposeful sampling (Patton, 2005) - selected university teachers, who have been involved in social media activities. These teachers used Facebook, LinkedIn and Youtube for sharing, communicating and collaborating with their students, colleagues and other self-regulated learners. After the first interview using snowball sampling, we selected new research participants to confirm, challenge and expand already collected data (Robinson, 2014). To overcome confirmatory bias in research participant selection and demonstrate wide range of perspectives, we followed Suri (2011) suggestions to choose the professionals that teach different fields and research subjects and have different social media experiences. Research participants' age varied from 23 to 62 years old. Their teaching and student mentoring experiences were from 1 to 36 years. During the interview, participants were questioned about their social media experiences (media channels, virtual activities, friending, and interaction) and situations where, why and how they experienced virtual connections.

Data analysis. We used grounded theory and started data analysis from the collection of the first interview. Data gathering, analysis and theory construction proceeded concurrently. We analyzed data inductively, comparatively, iteratively and interactively (Charmaz, 2006) and went back to collecting new data. We developed initial and focus coding following constructivist grounded theory procedures. During the initial coding, data were analyzed incident by incident. Focus coding allows to cluster data into structurally and thematically important parts. The clusters were not known in advance. They were constructed and re-constructed during recurring data collectionanalysis cycles. The text and visual memos about the research participants, researchers and data were continuously mapped and later used to interpret the data. These memos allowed researchers to conceptualize the data in a narrative and visual form. We 
searched for patterns and variations in data and collected new data till theoretical saturation (Lampert, 2007).

Ethics. Before starting the interviews, research participants were informed about the research purpose, anonymity in data collection and results publicity procedures. Although there were several participants from the same institution and there was a chance that some of them could possibly know each other, research participants were not aware of each other's participation in the study. The participation in the study was voluntary. During the interviews, academic and professional ethics were observed. University professors were asked not to mention student and colleague names or other institution related information. Interview questions were not announced in advance even if research participants asked for this. Data were audio-recorded with research participants' permission.

\section{Results}

Social media are extremely popular in our days for the possibility to reach people openly - it is easier to share, create, modify and discuss educational content, as well as network. Our research results showed how the academic connection for collective creativity in social media was maintained. We constructed three main categories: exploratory behavior; online presence; curiosity and challenge. Exploratory behavior was more typical for less social media experienced persons with less virtual friends. When a university teacher started new communication, was involved in the new virtual groups or gained new friends - the exploratory behavior was observed. Exploratory behavior in social media can be split to two subcategories: text hunting and checking text validity. Text hunting is the activity that teachers develop while preparing for lectures, classes or workshops. Some university teachers searched for information and scientific proofs. Others search inspiration for active class activities or newest practical examples for lectures. Teachers maintained that they found and adapted information from nonscientific networked sources:

I watch the news, films, go to the cinema and collect the information. I collect the information I could use it in the lectures for students. I do the same in social media. If I find something, I use this for my class discussion. For example, the link to foreign authors article. ( $K V$, female, 18 years' experience in higher education)

Knowing that in social media "it was possible to find everything, and you could not trust everything you found", they checked text validity. Verification of the social media text validity was done by searching for similar information in scientific online sources and checking out in several different documents or texts:

I use a page where I could find various links or methodological instructions, how to deliver a lecture and a lesson. Last semester I had lectures. I was looking at that page and was thinking what I could apply in terms of the information, provided in that page. Obviously, I must be sure that the information provided in the network is correct before using it (TI, male, 8 years' experience in higher education).

Online presence transformed from exploratory behavior when university teachers tamed the social media, began to devote more time to them and connected to students. 
Results showed that the main reasons for university teachers' engagement in social media activities were sharing and networking. There were university teachers who shared main and additional study materials, lecture slides and links to deeper learning and tests in social media. All the research participants emphasized that the institution to which they belonged had virtual learning environment and they needed to upload learning materials to the learning environment. Teachers chose social media as additional learning space to share educational content. The main reason was the noncomplicated upload of texts and the possible reception and reading speed. Additionally, university teachers stressed that non-formal communication with the students and colleagues in social media was developed quickly and encouraged teaching and learning. Teachers shared and uploaded learning materials and texts in multimedia formats to students. They created specialized social media groups and channels and accepted not only the students they taught but also other adult learners:

$<\ldots>$ I have been using social media for many years. I began to observe how material could be passed on to students. <...> not just my students. Surprisingly I found that students from all over the world were following me. I do not know them, I do not know who they are. I myself am not connected to them virtually. They only observe my virtual content. (UJ, female, 25 years' experience in higher education)

I used to send e-mails to my students. Once per week. I wanted to add as much useful information as possible to that e-mail. In my lectures, scientific literature was important, but popular information was also needed. Students could not find everything in textbooks. I used popular science articles for teaching. I was sending them by e-mail. But how many links could you sent through e-mail? I'm not sure if the students will follow them. Mail is mail. Because of that I began to use social media. In social media I could upload a picture and present it in a fun way. My students could not only follow me, but write comments to me the same second they received my post. (DJ, female, 5 years' experience in higher education)

Networking with students is not a very popular activity for Lithuanian university teachers. Some university teachers don't connect with the students because they don't want to be observed. Others stated that they participated in the same channels without the connection or shared materials without networking. They shared teaching material, because they saw the sharing as means of keeping continuous contact with their students and maintaining academic connection:

$<\ldots>$ If the student wants to receive additional information - I am happy to offer where he or she could find that information. I am going to discuss it with the student and I am happy to devote my time to them (DA, male, 15 years' experience in higher education)

if I want to spread my study materials quickly, I use social media. If I upload it elsewhere (not in media environments) students may delay reading or even forget to read. And in social media - look, after a minute or two, somebody already read your texts. (SJ, female, 10 years' experience in higher education) 
Curiosity and challenge caught up more active social media users. They started following various format texts in social media, sharing and networking. Inspired university teachers pursued professional goals. University teachers described their professional development as growth and change. Some of them sought the change, wanted to develop smart devices and internet, social media, communication, professional skills and used different self-regulated learning strategies. Others found themselves in the role of an adult learner and enjoyed learning communities. Research participants emphasized that they learned not only from the texts but also from other members of the networked learning community and their students. Teachers changed the format of their formal lectures by using social media data during their teaching activities:

I let the students choose their own ways how they would like to receive the study material from me. <...> In addition, I demanded that my students publish their works online. After that, it was easy to check in the social media the novelty and innovativeness of their publications. It is easy to trace students' work on Google's index. (CG, male, 20 years' experience in higher education)

Constructing professional identity category explained how university teachers understand their professional identity changes in social media environment. Social media influenced personal and professional goals of research participants. Teachers found new scholarly texts, innovative data in social media and later had the possibility to apply these new data to class activities. Additionally, almost all research participants underlined the "self-disclosure" issue. Most teachers wanted to hide their personal information. They talked about saving their subjective thoughts, feelings and emotions. Some research participants drew a wall between "private" and "professional" profiles. Others, on the contrary, indicated that their personal and professional profiles merged:

The gap that was from the beginning, is diminishing. I use my personal profile also for work. Everyone is now getting into social media. Just attending one or another conference and talking about social media. <...> when you come back you try everything and you never know where the social media could bring you in your teaching activities. (JS, female, 2 years' experience in higher education)

Exploratory behavior, online presence, curiosity and challenge explained how university teachers maintained academic connection for collective creativity (Fig. 1).

The results revealed, that maintaining academic connection for collective creativity was a cyclical process that evolved in a few ways. The learners went forward and backward with new knowledge and professional skills, repeated the same path or chose a new one. The arrows indicated the direction of the adult self-regulated learner professional or personal development in social media. An unbroken line indicated that the process or activity was observed in all the findings. The dash line showed that process was indicated only in some research participant samples. Two sub-cycles were observed: i) sharing, networking, maintaining academic connection for collective creativity and ii) pursuing professional goals, constructing professional identity, maintaining academic connection for collective creativity. These sub-cycles showed the never-ending process how university teachers developed collective creativity in social media. 


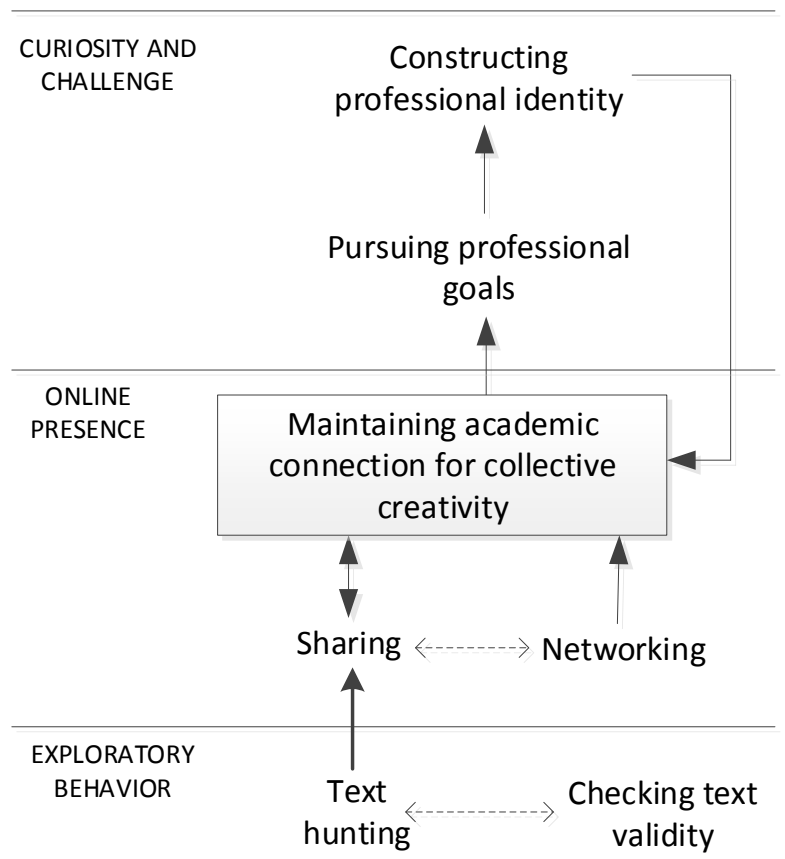

Fig. 1. Mapping the process how university teachers maintained academic connection in social media.

\section{Discussion}

We constructed a grounded theory of university teacher professional behavior in social media. Our results showed that collective creativity in social media happened at a level of virtual group and university teacher. Giuffre (2016) additionally noted two more levels: level of a culture and subculture. Our research was done in the context of academia that share a specific culture. In this research subcultures were not studied.

The categories that we constructed were of exploratory behavior, online presence, curiosity and challenge. Pelet et al. (2017) operationalizing the dimensions of creativity development in social media also mentioned curiosity and challenge as the highest dimensions of flow. In their investigation of role of flow, Pelet et al. (2017) proposed that social media produces emotional and cognitive experiences. Our empirical findings didn't cover control, concentration or enjoyment, but we expanded Pelet et al. (2017) model with exploratory behavior dimension. Our category online presence could be compared with mobile social media presence, researched by Gao and Bai (2014).

Main functional building blocks of social media in a consumer society were described by Kietzmann et al. (2011). We partly or fully covered four from seven functional parts of Kietzmann et al. (2011) framework: conversations, sharing, presence, and identity. Relationships, reputation and groups in social media and how they shape the collective creativity need more extended studies. Kietzmann et al. (2011) researched 
contrasting functionalities of presence, relationships, reputation, groups, conversations and sharing and their influence social media identity creation in Facebook, LinkedIn, and Youtube. We didn't consider the specific social media. Collective creativity results are unpredictable in many cases. From the research results it could be guessed that specific social media influence research participants behavior and shape collective creativity creation.

Limitations. This research was done in Lithuania and research participants were university teachers from Lithuania. Reaching broader research participant audience could enrich the research results. Innovative, initiative and active university teachers and scientists were selected for the research. Persons who spend their free time online and use social media for relaxation and entertainment were not considered.

Individual interviews were used as data collection methods. Social media analysis could help to better understand research participants and their living worlds. Quantitative research of broader audiences would fruitful the results and clarify the model of the process how university teachers maintain academic connection for collective creativity in social media.

\section{Conclusions}

The constructed grounded theory showed how university teachers developed collective creativity. Maintaining academic connection was the core category, explaining university teacher behavior. Three grounded theory categories: exploratory behavior, online presence, curiosity and challenge pointed the continuously developing process. Text hunting, checking text validity, sharing and networking were preconditions that lead to maintaining academic connection for collective creativity. Maintaining academic connection helped to pursue professional goals and construct professional identity. All the processes were cyclical. These findings contributed to understanding how the university teacher's collective creativity developed in social media.

\section{Funding}

This research is funded by the European Social Fund according to the activity 'Development of Competences of Scientists, other Researchers and Students through Practical Research Activities' of Measure No. 09.3.3-LMT-K-712. Research seeks to understand how self-regulated and social media competent students and teachers from gymnasium and universities construct their professional identities.

\section{References}

Charmaz, K. (2006). Constructing grounded theory: A practical guide through qualitative research. SagePublications Ltd, London.

Charmaz, K. (2014). Constructing grounded theory. Sage.

Crawford, B. (2015). Teacher professional development. Encyclopedia of science education, 10271029.

Csikszentmihalyi, M. (2014). Society, culture, and person: A systems view of creativity. In The Systems Model of Creativity (pp. 47-61). Springer Netherlands.

Fischer, G., Vassen, F. (Eds.). (2011). Collective creativity: collaborative work in the sciences, literature and the arts (Vol. 148). Rodopi. 
Gaggioli, A., Mazzoni, E., Milani, L., Riva, G. (2015). The creative link: Investigating the relationship between social network indices, creative performance and flow in blended teams. Computers in Human Behavior, 42, 157-166.

Gao, L., Bai, X. (2014). An empirical study on continuance intention of mobile social networking services: Integrating the IS success model, network externalities and flow theory. Asia Pacific Journal of Marketing and Logistics, 26(2), 168-189.

Giuffre, K. (2016). Collective creativity: Art and society in the South Pacific. Routledge.

Kietzmann, J. H., Hermkens, K., McCarthy, I. P., Silvestre, B. S. (2011). Social media? Get serious! Understanding the functional building blocks of social media. Business horizons, 54(3), 241-251.

Lempert, L. B. (2007). Asking Questions of the Data: Memo Writing in the Grounded. The Sage handbook of grounded theory, 245-264.

Miell, D., Littleton, K. (2004). Collaborative creativity: Contemporary perspectives. Free Association Books.

Miettinen, R. (2006). The sources of novelty: A cultural and systemic view of distributed creativity. Creativity and Innovation Management, 15(2), 173-181.

Papacharissi, Z. (Ed.). (2010). A networked self: Identity, community, and culture on social network sites. Routledge.

Patton, M. Q. (2005). Qualitative research. John Wiley \& Sons, Ltd.

Paulus, P. B., Nijstad, B. A. (Eds.). (2003). Group creativity: Innovation through collaboration. Oxford University Press.

Pelet, J. É., Ettis, S., Cowart, K. (2017). Optimal experience of flow enhanced by telepresence: Evidence from social media use. Information \& Management, 54(1), 115-128.

Perry-Smith, J. E., Shalley, C. E. (2014). A social composition view of team creativity: The role of member nationality-heterogeneous ties outside of the team. Organization Science, 25(5), 1434-1452.

Reusser, K., Pauli, C. (2015). Co-constructivism in educational theory and practice. International encyclopedia of the social and behavioral sciences, 3, 913-917.

Robinson, O. C. (2014). Sampling in interview-based qualitative research: A theoretical and practical guide. Qualitative Research in Psychology, 11(1), 25-41.

Suri, H. (2011). Purposeful sampling in qualitative research synthesis. Qualitative Research Journal, 11(2), 63-75.

Von Held, F. (2012). Collective Creativity: exploring creativity in social network development as part of Organizational Learning. Springer Science and Business Media.

Received June 19, 2018, accepted June 25, 2018 